\title{
Tribute to Jay S. Skyler, MD, MACP
}

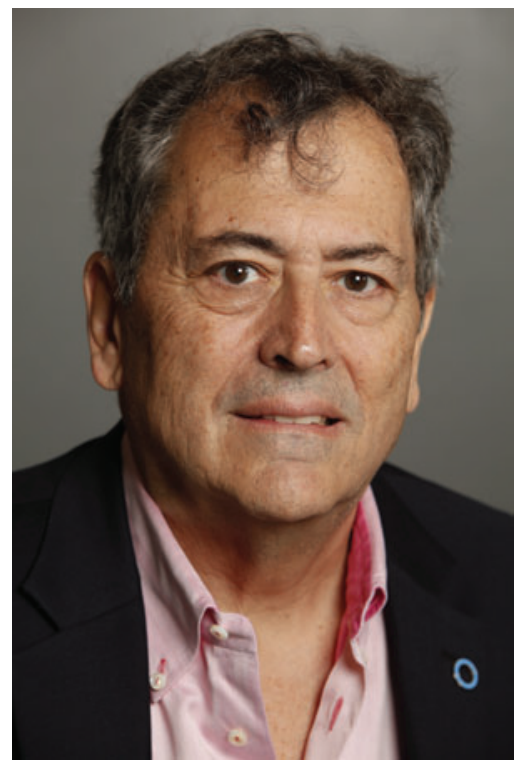

Dr. Jay Skyler has retired from his role as Senior Editor of Diabetes Technology \& Therapeutics after 15 years of service. The journal leadership team, the publisher, and the diabetes community are enormously grateful for his dedication and hard work. We hope that Dr. Skyler will enjoy the comments below from his colleagues, presented in alphabetical order. Knowing Jay, I am not sure he will ever retire. We will all miss him at DTT.

- Satish Garg, MD Editor-in-Chief

T IS A GREAT PLEASURE to say a few words about one of the major figures in diabetes of the past few decades.

My earliest memories of Jay were when we were both young diabetologists. I was invited to an insulin symposium in Miami where Jay presented pharmacokinetic data on Ultralente, requiring hourly blood sampling for well over 24 hours. He had the good sense to ensure that someone else took the samples! Another memory was at a meeting on home blood glucose monitoring in Melbourne, where Professor Paul Zimmet in the end presented each of us with a pair of boxing gloves, as we had disagreed somewhat vehemently during the meeting.

Jay's first major contribution, however, was as a dynamic and imaginative editor of Diabetes Care. In one of the first editions, he reproduced the excellent papers of Jean Pirart from Belgium, which showed in an uncontrolled but convincing way that glycemic control was related strongly to the development of micro- and macrovascular complications. This was a great service to English-speaking diabetes researchers.

Over the intervening years I have had many fruitful and entertaining discussions with Jay.

Over the decades Jay has made many contributions, particularly in the genesis and natural history of type $1 \mathrm{di}-$ abetes, and he shows no sign of slowing down. Congratulations, Jay.

George Alberti University of Newcastle upon Tyne United Kingdom 
Dr. Skyler will be retiring from his service as Senior Editor of Diabetes Technology \& Therapeutics, and I have been asked to describe his career in "just few words". That is an impossible task!

Even though I have not had the honor to be introduced personally to Dr. Skyler, I have followed his stellar career, like a timid but dedicated "fan", ever since I entered the world of diabetes technology some 20 years ago. Even before social media, here I was, trying to get my hands on every possible article Dr. Skyler penned or any lecture he delivered! You could call me a true 'follower'-this term was not even coined.

On the other hand, defining Dr. Skyler's impact on my career and my perception of this "Giant of Diabetes", is easy. It boils down to two words: awe and respect.

Author of hundreds of major diabetes articles, Founding Editor-in-Chief of Diabetes Care, pioneer in TrialNet research for over 20 years, with a never-ending list of accomplishments, Dr. Skyler has exemplified the ultimate diabetes researcher of the 20th century. He has made seminal contributions to the areas of diabetes at a time when the many facets of type 1 diabetes had not been fully understood, and when diabetes technology was in its infancy.

When there were no books on diabetes and technology, insulin pumps or CGM, and automated insulin delivery was still a "dream", attending Dr. Skyler's lectures during scientific meetings was "the" lecture not to be missed, where I could gather information otherwise not available.

One could describe his lecturing style as a mix of energy and stamina: a force of nature. I have seen Dr. Skyler deliver lecture after lecture regardless of whether we were in the US, or in Europe, no jet leg in sight, pure exuberance, wholly entrancing the audience. Because when Dr. Skyler delivers a presentation, you do not want to miss any words; you hang onto them as you are aware of the presence of a rare combination of expertise, knowledge, and humility. As you can imagine, I would sit in the front rows, in the hope to have the opportunity to ask Dr. Skyler more questions at the end of the presentation and learn more from him. Unsurprisingly he was always surrounded, so that task was practically impossible! I did at one time, however, succeed and had the chance to ask him questions, taking furious notes once I got back to my seat! He was generous with his time, but this is also not surprising.

His scientific generosity is unsurpassed: promoting new journals, including Diabetes Technology \& Therapeutics, spearheading new research and clinical projects, pioneering new treatment modalities, supporting the development of new technologies - all these represent who Dr. Skyler is.

Lastly, I personally had the chance to experience that he truly cares for his patients. I had the pleasure of inheriting one of his patients who moved from Miami to Chicago; he spoke so very fondly of him and asked me that if I ever saw Dr. Skyler at a conference, I was to make sure to send him his regards. So, when I had the opportunity to say a timid "hello" during an EASD conference in Barcelona, Spain a few years ago, I told him that one of his former patients was "saying hello ". Not surprisingly, he remembered! That moment was priceless.

I can say that Dr. Skyler, unbeknownst to him, has been a "virtual" mentor to me, and I can only thank him for his phenomenal accomplishments and advances in treating dia- betes that have benefited not only myself, but a lot more people he will ever know. As we say in Italy, 'Grazie!', 'Thank You', for your contributions; the world of diabetes is better because of you.

\section{Grazia Aleppo \\ Northwestern University \\ Chicago, IL, USA}

My favorite personal story about Jay (I wonder if he will remember this!) concerns a flight to London, on which we met - after all, where else to go to meet Jay? - unexpectedly, having attended different meetings. We were seated together and were comparing notes on our meetings when Gianfranco Bottazzo wandered down the aisle, having been at a third meeting in the same city. I cannot remember exactly the words Jay used to explain why we were traveling together, but I hope it never got back to George! Typical Jay - always humorous and quick-thinking and able to make the most of any opportunity. Although never otherwise duplicitous, of course. A polymath who never hesitates to get involved and who is thus able to speak authoritatively and with sparkle on so many topics in diabetes.

Congratulations on a great job done for DTT, Jay. It is hard to imagine you retiring from anything, but $\mathrm{I}$ bet it is just to allow you to take up something new. Very best wishes for your next project(s)!

\section{Stephanie Amiel Kings College London United Kingdom}

I first met Dr. Jay Skyler 20 years ago. Jay was the medical and clinical advisor on the Dexcom board. I was the clinical and regulatory executive at Dexcom. Over the last 20 years, Jay has been a board member, clinical advisor, and a key opinion leader in the diabetes field. I have had the privilege to work with Jay during this time. His contributions and advice have been so valuable in the development of the Dexcom CGM, but most importantly in the medical advances in treating diabetes. His clinical and medical advice to me was so helpful in designing our CGM clinical trials, as well as in recommending clinical sites for our studies.

Jay is always thinking about improving patient care for people with diabetes. His passion to keep up with the latest technology and advances is second to none in my mind. You can always depend on Jay to keep folks updated on the latest news in diabetes or other medical topics relevant to improving the lives of patients with diabetes.

At conferences I was very impressed with the energy that Jay had: ADA, ATTD, and many other venues. No matter what time it was, a 5:30 a.m. seminar where he is a speaker or a 6:30 p.m. debate, you would find Jay participating in the meeting either as a speaker or asking questions. He provided such inspiration through his passion to keep up with all the latest technology and to be present at the conference sessions and seminars. Of course, if I had a question about a specific point in the meeting, Jay would provide the insight to clarify the issue. 
There is no need to mention all of Jay's wonderful accomplishments in the field of diabetes and medicine, as there are too many to mention. He has been a key opinion leader in the field of diabetes for decades, authored and reviewed numerous publications, and he has continued to push both industry and the medical field to improve patient care. I cannot find enough words to describe the impact he has had in the field of medicine, especially in treating diabetes.

It is always a pleasure to be around Jay as you always learn a little tidbit of information you never knew before.

Jay, it has been an honor to know you and work with you over the past 20 years.

\section{Andy Balo \\ Dexcom, Inc. San Diego, CA, USA}

Jay Skyler has been a pioneer in type 1 diabetes for decades. Perhaps best known for his leadership of the Diabetes Prevention Trial and TrialNet, his influence has been felt throughout all facets of diabetes. He has been a strong proponent of randomized trials and has had a leadership role in many trials over the last 40 years. It is difficult to focus on any specific contributions Jay has made as they are too numerous to cite. A key area of his research has focused on pharmacologic treatments to alter the immune process in type 1 diabetes and here his contributions have been immense.

Jay has been active in the ADA, among many organizations for which he has provided service. He also has lent his expertise to many companies involved in the development of drugs and devices to help the lives of patients with diabetes. In addition to all of this, Jay has been an educator and mentor and has been responsible for training and advancing the careers of many endocrinologists. Jay has had an important role as a senior editor for Diabetes Technology \& Therapeutics for many years. His wisdom and insights will be missed but we know where to reach him in a time of need.

\section{Roy Beck \\ Jaeb Center for Health Research Tampa, FL, USA}

I am told Jay Skyler is leaving the position of Senior Editor of Diabetes Technology \& Therapeutics, and I'm given the opportunity of greeting Jay on such an occasion.

I first met Jay forty years ago, the first year of presidency of Ronald Reagan. Jay was coming to Italy as an invited speaker to a pioneer meeting in Assisi "Artificial Systems of Insulin Delivery", organized by the University of Perugia. As a young researcher with quite limited international experience, I was attracted by the big names of people at that time in metabolism and bio-engineering research, namely Jack Gerich, George Alberti, Michael Albisser, among others. However, my curiosity was captured by the speeches, the comments and, overall, the vivid personality of young Jay Skyler about topics such as artificial pancreas, pumps for continuous subcutaneous insulin infusion, and precursors of glucose sensors. That September 1981 has remained memorable for me: not only had I watched at the television Simon
\& Garfunkel playing the concert in the Central Park in New York City, but I had also met Jay. Soon upon receiving an invitation to submit an original paper, I learned Jay was the first Editor of this newborn journal, Diabetes Care, quite unknown at that time. In the subsequent years, I have witnessed the rapid success of the journal under the editorship of Jay.

Ever since, I have been in contact with Jay, either directly or indirectly by reading his innumerous papers, listening to the hundreds of presentations at the ADA and all sort of other meetings. What I have always admired about Jay, has been his ability to deliver lectures on a wide array of topics, moving from immunology to clinical therapeutics, from prevention to treatment of diabetes, and so on. He is not monothematic in research (as I consider myself), but universal, and able to quickly move across different fields of science, always with competence, information, authority, and delivery of long-lasting take-home messages. I consider this ability unique and extraordinary.

It would be difficult for me to list all the important scientific contributions of Jay. Other colleagues and friends, I am sure, are going to do this. Today Jay retires as senior editor of DTT.

We are all looking forward to Jay's future contributions, still many to come I am sure!

Ciao Jay, ad majora!

\section{Geremia Bolli \\ University of Perugia Perugia, Italy}

\section{Jay Skyler - The Ultimate Teammate}

Jay Skyler and my career were loosely connected in my youth. I have the vaguest recollection of Jay on the interview circuit looking for his first faculty appointment visiting with my parents who tried to recruit him in Charleston in 1975. As a MD, PhD student at Duke, I often heard a mention of Jay's exploits as I traveled in his wake. That said, I only knew his name and his scholarship until I was in my mid-30's. Everyone has had the experience of meeting someone respected from afar for the first time and being shocked. When I first got to know him personally in the early 1990's, it was inconceivable to me that "Dr. Skyler" was so young and willing to engage a young squirt like me. And for the last 30 years I have valued his friendship, advice, and insights.

Jay's ability to combine serious scholarship, leadership, and genuine friendship with so many people has been his defining characteristic. In that way, he is the ultimate "teammate". Whether as leader or follower, his contribution and conviviality are unparalleled. His concept of "team" variously has included collaboration with investigators from other disciplines, among multiple institutions, with companies, and most importantly the teamwork required of patients and providers working together. And with this team-based approach, Jay has innovated serially in various settings in ways that have changed the field of diabetes forever.

From Jay's first "diabetes summer camp" experiences as a fellow, he reported on increased independence of campers in managing their diabetes after attending summer camp. He was one of the first to recognize that the top-down style of diabetes management in which the doctor prescribed 
treatment and the patient's job was to comply was inherently flawed. He was also one of the first to examine the behavioral aspects of diabetes management and to embrace the concept of diabetes self-management. As the founding editor of Diabetes Care, through the late 70's and early 80's he used it as an instrument to extend this focus through a series of important papers that established the current tenets of modern diabetes management such as patient empowerment, peer support, glucose monitoring, insulin dose self-adjustment, insulin pump therapy, glycemic targets.

He performed some of the earliest comparative research studies examining how various techniques and products performed relative to each other in clinical practice. This early portion of his career is remarkable as the seminal Diabetes Control and Complications Trial would not be completed for more than a decade later. In the 1980's and beyond, Jay continued his clinical studies on optimal treatments in diabetes focusing on pregnancy; diabetic neuropathy, foot ulcers and cardiac autonomic neuropathy as well as diabetic kidney disease describing and debunking various clinical techniques in diabetes care and establishing much of the current management of the complications and comorbidities of diabetes. For me, as an MD, PhD student and later house officer and fellow focused on diabetes, his publications had a huge impact on my thinking as his words rang so true with my experience.

Most people have forgotten Jay's role as the premier clinical care thought leader of a generation ago and do not realize how his engagement of the broad diabetes community and writing was formative of our current standards of care.

Jay is most widely recognized for his work on the immunology of type 1 diabetes as a means to prevention. After leading or participating in a series of studies aimed at prevention or cure of type 1 diabetes since the mid-1980's, in 2001 he was successful in establishing a national consortium funded by NIDDK. TrialNet has been hugely successful, recruiting hundreds of thousands of participants over two decades. His vision and leadership were critical elements in establishing this explicit collaboration of patients, families, mechanistic scientists, trialists, clinicians, companies, foundations, and government agencies. In 2021, we may have the first FDA-approved treatment to prevent or delay type 1 diabetes based on his effort.

But my strongest impression of Jay is as a great friend. Whether on business travel, a long weekend get-together, or a vacation, Jay, Mercy, and their extended family are outstanding hosts and companions. We get a few hundred holiday cards every December, but Jay's is consistently the loveliest photograph presented with pride in his and Mercy's large and growing family. So to close, Jay, cheers to you as you give up another task! Just because you are stepping down, you must know that you cannot step away. Love you, be well and keep the holiday cards coming.

John Buse University of North Carolina School of Medicine Chapel Hill, NC, USA

Diabetes Technology \& Therapeutics, the only peerreviewed journal addressing all aspects of diagnosing and managing diabetes with cutting-edge devices, drugs, drug delivery systems, and software, has just bid farewell to their outstanding Senior Editor, Dr. Jay Skyler. This is relevant because Diabetes Technology \& Therapeutics has become an increasingly important journal in the current and expanding world of diabetes science and medicine! Dr. Skyler is a welldocumented pillar of knowledge in diabetes science, drug and device development research, and clinical care.

Having worked closely with him for nearly 15 years as a co-chair for the Cardiometabolic Health Congress, I've been privileged to witness his breadth of diabetes knowledge and its implementation to people of all ages living with diabetes. Moreover, his track record speaks for itself. Jay is currently a Professor of Medicine, Pediatrics, \& Psychology, in the Division of Endocrinology, Diabetes, \& Metabolism, Department of Medicine, University of Miami Miller School of Medicine where he served as Director of that Division from 2000 to 2004. Until very recently he was Chairman of the NIH (NIDDK)-sponsored Type 1 Diabetes TrialNet, an international network conducting clinical trials to prevent type 1 diabetes or modify the natural history of the type 1 diabetes disease process. His research interests have been broad-based and relate not only to the metabolic aspects of the disease but the psychosocial and behavioral support so often lacking in many clinical settings wherein we all work.

Jay is a past President of the American Diabetes Association, the International Diabetes Immunotherapy Group, and the Southern Society for Clinical Investigation, and was a Vice President of the International Diabetes Federation. He served as a member of the Endocrinology, Diabetes, and Metabolism Subspecialty Examining Board of the American Board of Internal Medicine, as Chairman of the Council of Subspecialty Societies of the American College of Physicians (ACP) and a member of the ACP Board of Regents. Looking back, it remains hard for me to imagine the academic legacy of Diabetes Care, a journal he founded as Editor-in-Chief in 1978. I remember this so well as I was entering my third year of fellowship training in endocrinology and metabolism at the University of Washington in Seattle at that time.

Hey Jay, you've done a spectacular job at Diabetes Technology \& Therapeutics, and the international cadre of diabetes scientists, clinicians, and people living with diabetes and their families and friends appreciate your contributions. Your esteemed career continues and I wish you the very best to follow!

\section{Robert H. Eckel, MD University of Colorado Anschutz Medical Campus Aurora, CO, USA}

Jay Skyler... Where do I begin after staring at my empty word document for half an hour? Jay has been at the forefront of diabetes for as long as I can remember and has made such a significant impact on the field in so many ways. He also positively affected scores of medical students, residents, fellows, faculty and individuals in the device and pharmaceutical industry.

My first interaction with Jay was when I was a junior faculty member at UCSD and was asked to give a lecture in Miami in 1993. Jay picked me up from the airport in his small 
economy car and on the way to drop me off at the hotel, we made a stop at one of his patient's house to pick up a urine collection to drop off at the lab. The patient was worried about her kidney function and had no transportation. This story sums up the personal nature of Jay, very warm, caring and the type of person who would do anything to help anyone in need.

I cannot remember any national meeting where Dr. Skyler was not chairing and or speaking in a major symposium. Jay knew how to moderate better than anyone to keep the focus on the topic and stay on schedule, a unique talent! When I think of type 1 diabetes, I think of Jay Skyler. When I think of type 2 diabetes, I think of Jay Skyler. Amazing that Jay could go both ways and be a true key opinion leader in almost any aspect of diabetes clinical and basic research as well as clinical care.

Generosity is also one of Jay's most impressive virtues. Jay and Mercy have opened up their home, on too many occasions to count, and always made their guests feel so comfortable. Their hospitality is second to none. Incredible food, open bar, great cigars and, most important, engaging and unimpeded conversation. I cannot think of a single individual inside or outside of the diabetes world who is as impressive an individual as Jay Skyler. There is no way he can retire. His mind is just too active. Jay is a thinker and always will be. I am privileged to call Jay my friend and colleague. Lastly, he is damn lucky to have Mercy as his better half as well!

Steve Edelman University of California, San Diego San Diego, CA

I have known Jay Skyler professionally for over twenty-five years. The first time I met him was at an investigator's meeting in Scottsdale, Arizona held by Eli Lilly on insulin lispro. Since then, we have interacted many times at various academic and research forums. He has also been a mentor to many of us and many of our colleagues.

$\mathrm{He}$ is the founding Editor-in-Chief of Diabetes Care. The journal's growth and circulation status are both a testament to Jay's incredible passion and drive in the field of diabetes. Diabetes Care is still one of the highest circulated journals in the field of diabetes and metabolism.

Fifteen years ago, I took over as Editor-in-Chief of Diabetes Technology \& Therapeutics (DTT) and invited Jay and Irl Hirsch as Senior Editors. Jay acted as Editor-in-Chief for all of my manuscript submissions to DTT. When I asked him to write a commentary on any topic, he would form a wellresearched and thought-provoking opinion. I still remember so vividly how the three of us (Jay, Irl, and myself) wrote an editorial regarding glargine and cancer. The three of us worked on a holiday weekend around July 4th and it was uploaded to the DTT website in three days.

Since 2012, I have relied on Jay's help and enthusiasm while creating the agenda for the Barbara Davis Center for Diabetes' and University of Colorado Denver's "Practical Ways to Achieve Targets in Diabetes Care" (ATDC) conference held in Keystone annually for the past $30+$ years. This CME-accredited conference attracts over 600 attendees who work in the field of diabetes or care for patients living with both Type 1 and Type 2 diabetes. I know I can assign him any topic and he will rise to the challenge, even though his primary interest is in immunology and diabetes. He has given several lectures on diabetic retinopathy, other microvascular complications, and cardiovascular disease and Type 2 diabetes. He is an amazing orator and engages the audience very well. He routinely receives top scores from the majority of the ATDC participants.

As many of you know, Jay has truly become a model of a family man. He enjoys hosting his extended family, including grandchildren, both in Miami as well as in Basalt, CO. It's always fun when Ralph DeFronzo and he spend time together just before the ATDC conference. They have great stories to share after every meeting. The only thing missing that I can think of in Jay is that he doesn't golf. Maybe he'll take up the hobby now with all the extra time from giving up the Senior Editor position at DTT. To the best of my knowledge, I've never seen him golf.

I know that Jay will never really retire, and when DTT needs help, we will reach out for his knowledge, thoughtful commentary, and guidance in the ever-changing field of diabetes technology and therapeutics. We will all miss him from the editorial board of DTT and wish him the best in life.

\section{Satish K. Garg, MD \\ University of Colorado Denver Aurora, CO, USA}

It has been a true honor and privilege working with Dr. Jay Skyler for 36 years. Jay was one of my first (and most important) mentors after my graduation from medical school. I remember those first years after medical school in Miami very well. Jay was the foremost expert in the new world of "intensive insulin therapy" and his compelling arguments that improved glucose control would slow or prevent the occurrence of diabetes complications were prophetic. Young physicians today will find it difficult to believe that the controversies of the mid-1980s were not conspiracy theories about light beams causing California wild-fires, but rather if nearnormal HbA1c levels with higher risks of hypoglycemia would result in longer lives and as importantly, better quality of life.

In many ways, we (and our patients) owe much of the success of diabetes to Jay. Jay's multidisciplinary clinic giving non-physicians the primary role of the diabetes clinician paved the way for the Diabetes Control and Complications Trial (DCCT). In fact, his book "Intensive Insulin Therapy" written with another mentor, Julio Santiago, in addition to Robert Rizza and David Schade, was a specific roadmap for the DCCT ${ }^{1}$. I believe I have the only copy signed by all four authors.

Of course, the DCCT was a dramatically positive study, and how to translate a clinical trial into daily practice was Jay's next challenge. First, teaching how to best use insulin analogues, then pumps, and eventually continuous glucose monitoring systems, Jay was able to lead the medical community to new levels of clinical excellence. I am not convinced we would have automated insulin delivery today if not for Jay's international leadership. Through all of this, his parallel research interest moved to the immunology of type 1 diabetes with the goal to modulate the immune system to slow the beta-cell attack. 
We are all grateful for all of Jay's contributions to diabetes and his role as senior editor of Diabetes Technology \& Therapeutics. What I am personally grateful for is the multidisciplinary team he led in the early 1980s. He hired a nurse who decided to leave Miami with me in 1987. Thank you, Jay, for all of your work in diabetes and allowing me to take Ruth with me from Miami!

\section{Reference}

1. Schade DS, Santiago JV, Skyler JS, Rizza RA: Intensive Insulin Therapy. Excerpta Medica, Princeton, 1983.

Irl Hirsch

University of Washington Seattle, WA, USA

I want to congratulate Jay on his many years of service to Diabetes Technology \& Therapeutics and extend my personal thanks to him for his many remarkable contributions to the journal and to the diabetes community.

Jay has been a remarkable friend and mentor - and as one who still considers myself "new" to this field (even after 40 years), am incredibly grateful for his guidance, his leadership and his untiring commitment to improving the lives of those affected by diabetes.

Even as a young trainee, Jay made me feel welcome in this great community of clinicians and scholars. He has been a remarkable mentor, teacher, and leader. His myriad contributions to care and education, as well as the dissemination of novel clinical findings, is testament to his commitment to innovation and scientific exchange. Beyond that, I have been fortunate to be a "student" of Jay and he has warmly and willingly shared with me and countless others his knowledge, his opinions (of which he has many!) and his warmth. The great world of diabetes care, research, and education is so much the better for all of Jay's work. Thank you, Jay, for a job superbly done.

\section{David Kendall, MD Zealand Pharma Westlake Village, CA}

'L'union fait la force' (Stronger through being united) is the motto of Belgium but it could have been the motto of Jay Skyler. All through his clinical and scientific career Jay has tried to move the field of diabetes forward through clinical and scientific collaborations. His advice and vision in many undertakings has shaped how our world of diabetes care and research looks today. He recognized the importance of evidence-based medicine and the need to demonstrate in a scientific manner what clinicians 'felt' or 'observed' in their daily life. In this vision, he has conducted many trials targeting prevention of complications in people with diabetes especially in trials attempting to arrest type 1 diabetes.

In the vision of a need for scientific evidence to guide diabetes care, he was the founding father of the journal Diabetes Care, recognizing a need for a forum for discussing data with direct relevance for diabetes care. The same hap- pened when he recognized the importance of diabetes technology in diabetes care, with his function as Senior Editor of Diabetes Technology \& Therapeutics.

His clinical expertise and vision have made him a valued advisor to many companies, thus helping realize projects that resulted in the availability of valued tools to help treat people with diabetes in a better way and in particular helping to improve their quality of life. Again, he has also tried to convince industry of the need to design relevant clinical trials to prove value of novel drugs and tools. His presence on many advisory boards is a proof of the respect the field has for Jay. Not always did industry follow Jay's advice, but instead of shouting and screaming, Jay's statement 'Oh well...' was often sufficient to convince upper management that he was right, thus putting his stamp on their trial design and path forward.

Perhaps the biggest sign of the 'unity' that Jay has tried to create in the field of diabetes research, and in particular type 1 diabetes research, has been the creation of TrialNet (through the DPT1 study). This 'well-oiled machine' for clinical trial conduct in type 1 diabetes, targeting the prevention or arrest of the disease has proven to be of immense importance to bring evidence on therapies that might work or, as importantly those that do not work and thus advance the field towards a cure. Fortunately, Jay has not limited his vision to the USA. He is a citizen of the world, and we as Europeans have eagerly taken his advice in many of our projects, like NAIMIT, INNODIA and INNODIA HARVEST, where his chairing of the Strategic Advisory Boards has helped shape our undertakings in trying to better understand type 1 diabetes, biomarker discovery, and in particular the design of a clinical trial network. Based on his experience with TrialNet, Jay advised us how to set up the network and be innovative in the design and execution of our clinical trials, as well as in how to collaborate between academia and industry.

Never has Jay refused an invitation to join our Advisory Board meetings in Europe. Of course, the fact that we give him an excuse to come to our continent, with great food and great hairdressers, may help. We hope that Jay may continue to put his stamp on diabetes research for many years and continues to be the 'bridge builder' and 'facilitator' bringing the right people together at the right time and wish that we can all work together towards our big goal: preventing and curing type 1 diabetes. One hundred years of insulin is enough...

\section{Chantal Mathieu INNODIA Belgium}

\section{Dear Jay:}

As you are stepping down from your mission as a senior editor of Diabetes Technology \& Therapeutics, which is the official journal of ATTD, it is time to review your long-time contribution to several publications. In the 12 years that you held this position, you have added a lot of value to the journal. This was not the first time: you were the cofounding Editorin-Chief of Diabetes Care, back in 1978 and you were involved in many other journals.

It is so hard to summarize the infinite doings of a person like you in just a few words. I would highlight just some of 
them. You have been active and served in various roles at the American Diabetes Association (ADA), the International Diabetes Association (IDF), the European Association for the Study of Diabetes (EASD), the council of the Immunology of Diabetes Society (IDS) to the International Diabetes Immunotherapy Group (IDIG), and so many more. The latter two societies are examples and may represent the role that you have been leading in this world of diabetes, namely focusing your research in modulating the type 1 diabetes process by means of immunoregulations. It seems that your heart was in the place where you really wanted to define the natural history of diabetes and its pathophysiology, where you could find ways to prevent the development of diabetes and intervene at the process, thus finding a CURE to type 1 diabetes.

You have been serving more than 20 years with research and studies via the NIH-sponsored Diabetes Prevention Trial (DPT-1) and the NIH Type 1 Diabetes TrialNet Clinical Trials Study Group. The same dream is underlying your joining INNODIA, a European consortium of academic and industry groups of which the goal is "to fight type 1 diabetes".

Yet, you also did put a lot of effort in clinical studies with the aim to improve the treatment for people with diabetes. In an interview from 2014 you mentioned that one of your biggest achievements is that you "happened to be one of the first investigators to introduce patient self-monitoring of blood glucose". This led to developing algorithms for patients to adjust their insulin dose and manage their disease. You have written papers on this topic and as a result they became the guidelines for self-monitoring of blood glucose manufacturers. Someone even called them 'Skyler algorithms'. Eventually, it also became a part of the Diabetes Control and Complications Trial (DCCT). Further development in this direction led to emerging technologies for the use in the treatment of diabetes, from pumps to continuous glucose monitoring and eventually to closing the loop or as we also call it "artificial pancreas".

Jay, you received so many awards; you were and still are a member of so many societies and research groups; you had so many publications; you were involved with the industry in advancing treatment methods and therapeutics - you have really accomplished so much!

All I can say now is: continue in your wonderful path that you have been going all along, with the same enthusiasm and pace. There is still a lot to be done and you can contribute a lot.

With warm regards to healthy and happy years.

\section{Moshe Phillip \\ Tel-Aviv University \\ Tel-Aviv, Israel}

\section{A Salute to Jay Skyler}

I first met Jay one morning 43 years ago when he visited us in London to see what we were doing with a new technique for improving glycemic control in type 1 diabetes. We were calling it continuous subcutaneous insulin infusion, but not expecting the name to stick. I remember that afterwards we lunched at the George Inn, at the back of Guy's Hospital. This famous Elizabethan watering hole - the pub, not the hospital - has seen many a notable clientele, including (most likely) William Shakespeare and (certainly) Charles Dickens.
However, from our point of view, history might also have noted that the landlady of the George would be one of the first people in the world to use an insulin pump outside of a hospital, but I don't think that was mentioned.

During our lunchtime conversation, it emerged that Jay and I were the same age (we still are), though I remember him saying I looked younger - I think he meant immature. Jay had just started as the first editor of the newly created ADA journal Diabetes Care which, even in its first issue, was featuring articles about new diabetes technology - jet injection of insulin and self-monitoring of blood glucose.

I learned a lot from Jay during that lunch that fed into our own work in 1978, as indeed I have in the many years since. He was, for example, already using blood glucose selfmonitoring for certain patients like pregnant women with diabetes. In fact, this was a technique known to us because of the trials being performed at our neighboring St. Thomas's Hospital, but it was not filtering through into clinical practice and was very much discouraged by some of the great and good of the British Diabetic Association. He also told me about the written rules they had developed for adjusting insulin dosages according to urine glucose tests, I think originating from efforts to improve control in diabetic children at camp. Shortly, these would be used for insulin adjustment using blood rather than urine glucose tests. I ruminated on these ideas and planned to make both home blood glucose testing and insulin adjustment essential components of outpatient continuous subcutaneous insulin infusion, as we begun to transform it from short-term experimental tool to long-term therapy option.

Fast forward then, more than 40 years and a lot of glycosuric water has flowed under the bridge since that first meeting with Jay. I reflect about that initial encounter and celebrate the support and leadership Jay has given to research and clinical practice over the years that followed.

Just in my own areas of interest, he has been a champion of intensive insulin therapy, by injection or pump; an early adopter of blood glucose self-monitoring; a pioneer of using that data for patient self-management; and a staunch supporter of the developing field of diabetes technology, often when at times it was receiving less than enthusiastic support from many in the medical profession. In particular, he has been a wise journal editor, who steered me in the right direction on many an occasion in those early days, and over many years he has brought advances in clinical diabetes research to practitioners worldwide. Diabetes Technology \& Therapeutics has indeed been lucky and privileged to have had the guidance and experience of Jay as Senior Editor, and I salute him and wish him well.

\section{John Pickup \\ King's College London London, United Kingdom}

I began my career as a physician scientist in the early 1990s. Then and now, Jay Skyler has meaningfully led the charge to improve the lives of people with diabetes. I am fortunate to live in Colorado; since my fellowship I have been on the planning committee for our annual Snowmass Diabetes and Endocrinology Update where Jay is often a 
speaker. In that setting I have had the chance to get to know Jay and his family and to be inspired by his passion for all things diabetes, a passion I share.

In the nearly 3 decades I have worked in the field, we have experienced many exciting changes in our understanding of diabetes (all sorts), many fits and starts in beta cell replacement and a revolution in the tools available improve the day to day lives of people living with diabetes. Jay has led many of these studies and championed integrating advances into patient care. He has created local and global forums to advise the world and its healthcare systems on new advances in diabetes. His contributions in the science of type 1 diabetes and progress of all diabetes research are TNTC.

But Jay is not stepping down because he is satisfied. We have not cured diabetes. We have seen a global explosion of the number of people living with diabetes. We have unacceptable inequity in health care for people with diabetes. The landscape for all people with diabetes is better because of the lifetime work of Jay Skyler and his impact on the field. He will continue to lead the field, with a few more ski days and hikes woven into the week.

Thank you, Jay!

Jane Reusch University of Colorado School of Medicine Aurora, CO, USA

I am pleased to add my thoughts to this tribute to Jay Skyler, MD. I first met Jay back at NIH in the mid-1970s. Jay was in the "Heart" institute (NHLBI) and I was in the "Child Health" institute (NICHD). Both of us were working in a protein physical chemistry laboratory that was pioneering the application of polyacrylamide gel electrophoresis for characterization, purification, and preparation of protein hormones. Jay was characterizing several new iso-hormones of human growth hormone in collaboration with Andreas Chrambach and C. H. Li.

Jay then moved to the University of Miami and became thoroughly involved in the development of improved treatments for diabetes. Jay was one of the four authors of a landmark book entitled, "Intensive Insulin Therapy," together with David S. Schade, Julio V. Santiago, and Robert A. Rizza. In the early 1980 s that book served as a "bible" that enabled me to develop several early software programs and analytical methods intended to assist patients and physicians in the management of diabetes. I developed data management systems for logging of glucose, insulin, diet, and exercise, display the data graphically and statistically, calculate insulin bolus doses, and make recommendations for choice of insulin regimens ranging from basal only to multiple daily injections. I proposed use of a simplified 4 or 5 points scale for diet and exercise instead of the notoriously inaccurate "carb counting'. I went on to introduce exploratory data analysis of glucose (nonparametric statistics, Box plots, use of the 25th, 50th, and 75th percentiles for glucose by time of day), and develop the Ambulatory Glucose Profile (AGP) as originally applied to capillary blood glucose and subsequently applied to Continuous Glucose Monitoring (CGM) data.

To this day I continue to utilize the wisdom of that book, and of many other major contributions that Jay Skyler has made to the domain of diabetes, endocrinology, and medicine. That book has served as the basis of much of my work over the past 35 years. Jay has always shown outstanding leadership in research, practice, and teaching. He is such an inspiring, effective, and entertaining speaker. Diabetes Care, our journal Diabetes Technology \& Therapeutics, and our readership, and the world in general owes Jay a great debt of gratitude.

\section{David Rodbard, MD \\ Biomedical Informatics Consultants LLC Potomac, MD, USA}

I have been involved in the diabetes industry for over 20 years, first as a part of MiniMed/Medtronic and now as the CEO of Dexcom. The first thing I think of regarding Dr. Jay Skyler is very simple - every time I have a question about something in diabetes technology or whenever something "new" or "game-changing" comes out - I call Jay and he explains it to me. It has been that way for my entire diabetes career. Jay has been involved in some way with every major innovation in diabetes care throughout my entire career.

Jay has had a profound influence on Dexcom as a member of our board since 2002. He is always engaged and completely prepared for our discussions; therefore - he ALWAYS has an opinion and, as everyone acquainted with him knows, he is NEVER afraid to express it. These opinions have caused us to think more critically about our decisions and have ultimately helped us become better as an organization. Jay's perspective consistently comes from the same place doing what's right for patients. He has held us to the standard that whatever is good for patients will be good for Dexcom. That said, sometimes being close to Jay can be a challenge if one of his patients is having trouble getting what they need from their insurance company on Dexcom products, he calls me directly. His commitment to patients is unwavering.

Very few individuals carry all of Jay's titles - physician, researcher, investigator, author, technologist, board member, teacher - and I am sure there are more I have left out. At many of our major diabetes meetings, when I meet someone new, I am often asked how I know Dr. Jay Skyler. The conversations quickly move to stories about Jay's effect on all our lives particularly those he has taught. He settles for nothing but excellence in all he does and is one of the few people that I know who has successfully navigated so many roles. We are all better for having worked with him and learned from him. All of us at Dexcom thank Jay for his contribution as Senior Editor of Diabetes Technology \& Therapeutics - a forum like this is absolutely critical to the changing technological environment we live in today. While we'll miss Jay deeply, the diabetes community has much more to do - and we'll try to live up to his example as we do it.

\section{Kevin R. Sayer Dexcom, Inc. San Diego, CA, USA}

I am very pleased to be able to pay tribute to Jay Skyler whom I have known as a friend and colleague for many years. His contributions to the knowledge and treatment of diabetes 
is legendary. I realize that at this time Diabetes Care is one of the most recognized diabetes journals. However, back when this journal was founded by the American Diabetes Association (1978), many skeptics did not believe it would survive. Of course, it did, but only because of the hard work and dedication of Dr. Skyler. As its first editor, I remember him calling his friends and colleagues and begging for articles for this new journal. Very few people would have had the dedication and perseverance to accomplish what he did. Since this time, Jay has branched out into many areas, including Senior Editor of Diabetes Technology \& Therapeutics. This journal is now "required" reading for all practitioners who treat diabetic patients. His skill and time commitment to this journal is one reason that it has become so widely read.

My closest professional contact with Jay was in 1982 when four physicians (myself, Julio Santiago, Robert Rizza, and Jay Skyler) got together in order to publish in the medical literature the importance of intensive insulin therapy. Jay not only was able to obtain funding for this book (an educational grant from Squibb Novo) but also contributed many of the chapters to its content. Every month for a year we all four traveled to Chicago to debate the content of the chapters and to verify the information in it. Thanks to Paul Haycock, MD from Squibb Novo (who also contributed a chapter), thousands of copies were distributed at no charge to professionals in the medical field. Nowadays, intensive insulin therapy is taken for granted but at the time, few publications were available for the practicing physician to learn about this topic. As is evident in the picture, Jay was a little younger but just as enthusiastic and intelligent as he has remained all these years.

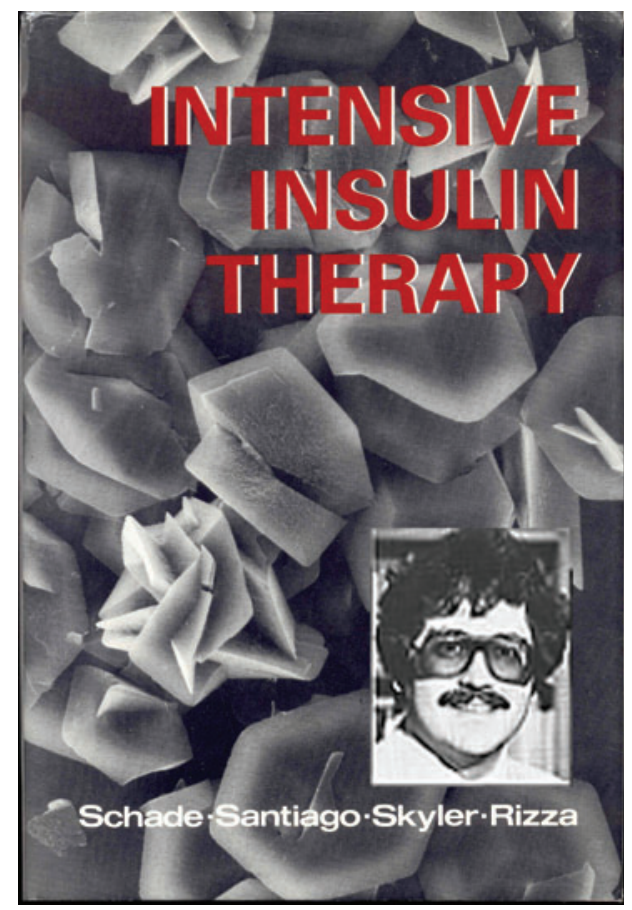

The cover of the book published in 1983 for which Jay played a major role. It set the stage for many future research studies such as the DCCT (1983-1993) as well as greatly improving the care of diabetic patients. It was one of the many accomplishments that made intensive insulin therapy a standard of care for physicians and practitioners worldwide.
It has been my great pleasure to know and respect Jay, not only for his contributions to diabetes knowledge, but also to be a friend of a fine individual.

\author{
David S Schade \\ University of New Mexico \\ Albuquerque, NM, USA
}

Jay has been a colleague and mentor of mine for over 35 years. He is internationally recognized as a pioneer of diabetology, a prolific educator and mentor, and an innovative developer of programs for both children and adults with diabetes. He has been a highly productive clinical investigator and is known as an ethical voice in the field who successfully challenges established ideas. His leadership in research, teaching, advocacy, and clinical care has clearly impacted and influenced the field of diabetes, as well as so many of us in academic medicine and clinical practice. His many original observations and insights in diabetes, together with his extensive lecturing, editing, reviewing, and leadership efforts have made him an internationally recognized educator, innovator, and investigator.

Until 2015, Dr. Skyler served as Chairman of the NIH (NIDDK)-sponsored Type 1 Diabetes TrialNet, a nationwide and international network conducting clinical trials aimed at ameliorating and preventing type 1 diabetes. Prior to that, beginning in 1993, he was Study Chairman for the nationwide multicenter Diabetes Prevention Trial for Type 1 Diabetes (DPT-1), the predecessor of TrialNet. I have personally known Jay for nearly 30 years and have collaborated with him on these NIH-funded Type 1 diabetes-related studies for the past 27 years. I worked with him closely in this regard. His leadership in the careful conduct of these important clinical trials was crucial to their successful completion, their publication in highly cited journals and, above all, the success of the networks. Under his leadership, no fewer than 13 major nationwide (and extending internationally) Phase 2/Phase 3 clinical trials aimed at either preventing or interdicting the disease at Type 1 onset were conducted. This is an extremely remarkable achievement, and one which would not have been possible without Jay's leadership.

Jay's career in diabetes spans five decades. His initial involvement in Type 1 diabetes immunology began in the early 80 s. Jay was awarded the first R01 by the NIH to study the effects of immune intervention on beta cell function in human beings with Type 1 diabetes. Those studies, first with cyclosporine, and subsequently with an anti-CD5-immunotoxin, helped establish that immune modulation preserved C-peptide secretion. These studies contributed significantly to the inception and launch of the DPT-1 study. Since that first award, Jay has maintained continuous and prolific funding from the NIH, either as a Principal Investigator and/or Study Chairman.

Jay Skyler's clinical research interests are broad: he has championed the cause and conducted studies aimed at improving the care of Type 1 diabetes through meticulous glycemic control, the prevention of micro- and macrovascular disease, and psychosocial and behavioral support. He has also long been interested in the complications of diabetes, and in the relationship between blood pressure and 
blood glucose. Jay was a pioneer in the use of patient selfmonitoring of blood glucose and in developing the intensive diabetes management concept for which he received international recognition for his development of algorithms for adjustment of insulin doses. For his numerous contributions, he has received many accolades, including the Achievement Award of the American Society of Contemporary Medicine \& Surgery "for Distinguished Contributions to the Knowledge of Diabetes Mellitus", the Plenary Medal at the 13th IDF Congress, and the Simon Gratz Medal.

In 2013, he was the first George Eisenbarth Memorial Lecturer for the Immunology of Diabetes Society and was the recipient of the 2014 Distinction in Endocrinology Award from the American College of Endocrinology. He was also the recipient of the 2015 Distinguished Faculty Scholar Award from the Faculty Senate of the University of Miami, the 2015 Mary Tyler Moore/S. Robert Levine Award for Distinction in Clinical Research from JDRF, the 2016 Alumni Achievement Award of Jefferson Medical College, and the 2017 Josiah K. Lilly Award from the American Diabetes Association. As a tribute to his institutional commitment, The Jay S. Skyler Visiting Professorship in Diabetes at the University of Miami was established in 2010.

Jay has served on the Executive Boards of many national and international organizations. He has served the American Diabetes Association (ADA) in many capacities, culminating in his election as the 50th national President and being the recipient of the Banting Medal for Service to the ADA. Jay represented the ADA on the Council of Subspecialty Societies (CSS) of the American College of Physicians (ACP) for six years, and he served as Chair of CSS and a member of the ACP Board of Regents. He was also Chair of ACP's Research Center Advisory Committee and a member of ACP's Oversight Group monitoring the Subspecialist/Generalist Interface.

He served a six-year term in the early 90 s as a member of the Endocrinology, Diabetes, and Metabolism Subspecialty Examining Board of the American Board of Internal Medicine (ABIM), and then served as first Chairman of the first ABIM Re-Certification Committee for Endocrinology, Diabetes, and Metabolism. He was President of the Southern Society for Clinical Investigation (SSCI) and served on the Executive Board and as Vice-President of the International Diabetes Federation (IDF). Dr. Skyler was also a founding member of the Executive Committee of the International Diabetes Immunotherapy Group (IDIG), serving subsequently as President for three years.

Although Jay is an Internist and Endocrinologist, he served as Director of a diabetes summer camp annually for 13 years, where he became recognized for using camp as a locus for training of medical and nursing students, house staff, and fellows. At the University of Miami, he initiated and for 10 years served as Director of the Diabetes Metabolic Unit. During his tenure as Director, that unit attained national and international prominence, being selected as the model diabetes unit to represent the United States at the Worldwide Diabetes Care Program held in conjunction with the 12th International Diabetes Federation (IDF) Congress in Madrid in 1985. Dr. Skyler directed the first program establishing standards for diabetes summer camps, as Chairman of the ADA Committee on Camps.

Jay Skyler's innovation was instrumental in starting several of ADA's publications. He was founding Editor-in-Chief of the ADA professional journal, Diabetes Care, serving five years in that position (1978-1982), during which time Diabetes Care attained the highest circulation of any journal in the field of Endocrinology, Diabetes, and Metabolism, a position it still holds. Then, during his tenure as Chairman of the Committee on Publications, he launched the ADA publications Clinical Diabetes and Diabetes Reviews, in which he subsequently served as Editor-in-Chief.

Jay is a prolific writer, editor, and speaker. He has been author, editor, or co-editor of 21 books or monographs, and has written over 525 articles, book chapters, or editorials. He serves or, at one time or another, has served on the editorial boards of 27 journals. According to Google Scholar, his publications have been cited over 15,400 times since 1974, and 5,940 times in just the past five years. His curriculum vitae lists multiple plenary addresses at national and international meetings, as well as Grand Rounds and Visiting Professorships throughout the world. His expertise is widely sought as a scientific advisor to the pharmaceutical, biotechnology, and medical equipment industries, as a member or chair of their Medical Scientific Advisory Boards; in fact, he has chaired advisory committees for multiple pharmaceutical companies.

In summary, Jay has been a mentor not only to me but also to so many in the field of diabetes. He has touched and improved the lives of both patients and professionals, as is evident in his continual influence on the field of diabetes and the esteem with which he is held by his colleagues. His many original observations and insights in diabetes, together with his outstanding academic contributions, extensive lecturing, editing, reviewing, and leadership efforts have made him an internationally recognized clinician, educator, innovator, investigator and, above all, friend.

\author{
Desmond Schatz \\ University of Florida Diabetes Institute \\ Gainesville, FL, USA
}

